\title{
Susceptibility to sensitization. II. The influence of gonadal hormones on enduring changes in brain monoamines and behavior produced by the repeated administration of D-amphetamine or restraint stress
}

\author{
Dianne M. Camp ${ }^{1}$ and Terry E. Robinson ${ }^{1,2}$ \\ ${ }^{1}$ Department of Psychology and ${ }^{2}$ Neuroscience Program, The University of Michigan, Ann Arbor, MI 48109 (U.S.A.)
}

(Received 3 November 1987)

(Revised version received 1 February 1988)

(Accepted 5 February 1988)

Key words: Amphetamine; Stress; Sensitization; Sex difference; Gonadal hormone; Dopamine; Serotonin; Striatum

\begin{abstract}
Repeated amphetamine use produces an enduring sensitization of brain dopamine (DA) systems and behavior. Repeated exposure to stress can also produce sensitization, and amphetamine and stress may be interchangeable in this regard. There is, however, enormous individual variation in the susceptibility to sensitization by either stimulants or stress. The purpose of the present study was to determine if endogenous gonadal hormones contribute to individual variation in the sensitization of stereotyped behaviors, locomotion or regional brain monoamine metabolism. It was found that removal of testicular hormones by castration of male rats facilitated the behavioral sensitization produced by either repeated amphetamine treatment or repeated restraint stress, but ovariectomy of female rats was without effect. Prior exposure to amphetamine enhanced striatal homovanillic acid (HVA) levels and dihydroxyphenylacetic acid to DA and HVA to DA ratios in intact female, ovariectomized female and castrated male rats, but not gonadally-intact male rats. As a group, intact males were particularly heterogeneous because they were divisible into two neurochemically distinct subgroups based on their degree of behavioral sensitization, and the other groups were not. It is suggested that individual differences in the sensitization of brain DA systems and behavior produced by repeated exposure to amphetamine or stress may be due in part to individual differences in the concentration of a testicular hormone.
\end{abstract}

\section{INTRODUCTION}

The repeated, intermittent administration of amphetamine (AMPH) produces a progressive and enduring enhancement in behavior elicited by

subsequent exposure to AMPH, a phenomenon called behavioral sensitization ${ }^{20,36,44,45,55,67}$, and this is accompanied by enduring changes in brain dopamine (DA) systems ${ }^{59}$. Most animals show

Correspondence: T. E. Robinson, Neuroscience Laboratory Bldg., The University of Michigan, 1103 E. Huron St., Ann Arbor, MI 48109, U.S.A. 
sensitization, but there is also enormous individual variation in the susceptibility to sensitization $^{41,47,53,66}$. In exploring what factors might contribute to this variation we previously found sex differences in behavioral sensitization, and some of its neurochemical correlates ${ }^{14,15,55,61}$. Most sex differences in behavior have been attributed to the action of gonadal steroid hormones, either during an early organizational period or in adulthood ${ }^{24}$, and the sex difference in behavioral sensitization may be due to a testicular hormone in adult males. This is because adult male rats gonadectomized (GDX) prior to AMPH treatment show greater sensitization of AMPH-induced rotational behavior than intact males, and do not differ from intact or GDX females $^{55,61}$. However, the contribution of gonadal hormones to the sensitization of other behaviors produced by AMPH is not known. It is possible that gonadal hormones affect the sensitization of stereotyped behavior and locomotor activity differently than rotational behavior, because AMPH produces its wide array of behavioral effects by altering activity in anatomically and functionally heterogeneous brain catecholamine systems ${ }^{19,30,35,73}$. Therefore, experiments were conducted to determine the effects of endogenous gonadal hormones on the AMPH-induced sensitization of stereotyped behavior and locomotion, and on associated changes in regional brain DA metabolism.

In addition, it has been suggested that the enduring effects of AMPH may not be unique to the psychopharmacology of AMPH, but due to its action as a stressor ${ }^{1,3,21,52}$. For example, repeated exposure to a variety of stressors enhances the behavioral response to a subsequent injection of $\mathrm{AMPH}^{4,28,57}$. Conversely, sensitization to AMPH enhances behavioral and neurochemical responses to subsequent stress $\mathrm{s}^{4,62}$. Therefore, the influence of sex and gonadal hormones on the behavioral sensitization produced by repeated exposure to restraint stress was also examined. It was hypothesized that if AMPH and stress are interchangeable in producing sensitization, then sex and gonadal hormones should have similar effects on the behavioral sensitization produced by previous exposure to either AMPH or stress.
EXPERIMENT 1: THE INFLUENCE OF ENDOGENOUS GONADAL HORMONES ON THE SENSITIZATION OF LOCOMOTION, STEREOTYPED BEHAVIOR AND BRAIN MONOAMINES PRODUCED BY REPEATED INTERMITTENT AMPHETAMINE TREATMENT

\section{Methods}

\section{Subjects}

The experiments were conducted with adult male and female Holtzman rats (Sprague-Dawley-derived; Holtzman Co., Madison, WI) weighing $250-300 \mathrm{~g}$ at the start of the experiment. All animals were housed individually in wire-hanging cages in a room that was maintained on a normal 14:10 light:dark cycle (lights on at $08.00 \mathrm{~h}$ ). Food and water were freely available. All testing was conducted between 09.00 and $16.00 \mathrm{~h}$.

\section{Apparatus}

Motor activity was measured using automated activity monitors. These consisted of wire-hanging cages $(41 \times 24 \times 18 \mathrm{~cm})$ equipped with two pairs of infrared photocell emitters and detectors situated along the long axis of each cage. The photocells were mounted $2.3 \mathrm{~cm}$ above the cage floor and $15 \mathrm{~cm}$ apart from each other, dividing the cage into a central area in which there was no photocell beam, and two $13 \mathrm{~cm}$ long areas to the extreme right and left of the cage in which the presence of a rat would result in disruption of the photocell beam. Disruption of a photocell beam was detected by a microcomputer (Commodore VIC20) that recorded the total number of photocell beam interruptions during each 5-min interval. Breaking one photocell beam registered a single count. However, another count could not be registered from the same beam until the second photocell beam at the other end of the cage was disrupted. Thus, activity counts in this apparatus reflect locomotion from one side of the cage to the other.

\section{Ratings of stereotyped behavior}

Stereotyped behavior was assessed visually using two different rating scales. The 9-point scale 
described by Ellinwood and Balster ${ }^{23}$ was used to estimate overall stereotypy. On this scale, 1 = asleep; 2 = inactive; $3=$ normal in-place activity; $4=$ normal, alert, active; $5=$ hyperactive; $6=$ slow patterned stereotypy; $7=$ fast patterned stereotypy; $8=$ restricted stereotypy; and $9=$ dyskinetic-reactive. In addition, various components of stereotypy, including repetitive sniffing, repetitive movements of the head and limbs, and repetitive oral behaviors (licking or biting) were individually rated according to their intensity $(1=$ mild, $2=$ moderate, $3=$ intense $)$ and duration $(1=$ discontinuous, $2=$ continuous), as described by Rebec and Segal ${ }^{54}$. For each measure the intensity and duration scores were multiplied together to yield a single stereotypy score at each time interval.

\section{Procedure}

To determine the influence of endogenous gonadal hormones on the development of sensitization, female and male rats were either gonadectomized (GDX), or received a sham operation under ether anesthesia. Ten days later the animals were habituated to the activity monitors for 8-12 h, and again 2 days later. Beginning two weeks after surgery the animals received an intraperitoneal (i.p.) injection of D-amphetamine sulfate (AMPH) dissolved in $0.9 \%$ saline once every 3 days for a total of 10 injections, followed 3 days later by a single i.p. injection of saline $(1 \mathrm{ml} / \mathrm{kg})$.

Intact male rats $(n=15)$ received $3.0 \mathrm{mg} / \mathrm{kg}$ AMPH (weight of the salt) on all 10 treatment days. The remaining 3 groups received a lower dose of AMPH than intact males, because testicular hormones accelerate AMPH metabolism, resulting in lower brain levels of AMPH in intact males than in females or GDX males given the same systemic dose ${ }^{7,18}$. On the basis of previous studies in which striatal and whole brain concentrations of AMPH were measured at various points in time after the i.p. administration of a wide range of AMPH doses $(1-10 \mathrm{mg} / \mathrm{kg}$ ), we determined that $2.6 \mathrm{mg} / \mathrm{kg}$ (i.p.) produces the same brain concentration of AMPH in intact female, GDX female and GDX male rats as does $3.0 \mathrm{mg} / \mathrm{kg}$ in intact males ${ }^{7}$ (also unpublished studies). Thus, for the first 9 days of drug treat- ment intact females $(n=15)$, GDX females $(n=15)$ and GDX males $(n=15)$ received $2.6 \mathrm{mg} / \mathrm{kg} \mathrm{AMPH}$. On the 10 th drug treatment day animals in these latter 3 groups received a lower challenge dose of AMPH $(2.0 \mathrm{mg} / \mathrm{kg})$. This provided an even more conservative test, because this dose would produce lower brain levels of AMPH in females and GDX males than in intact males given $3.0 \mathrm{mg} / \mathrm{kg}$.

Behavior was not monitored following every AMPH treatment, but only following the 1st, 2nd, $3 \mathrm{rd}, 4$ th, 7 th and 10th treatments (test days). On test days the animals were placed in the activity monitors and allowed $1 \mathrm{~h}$ to habituate. Then they received the injection of $\mathrm{AMPH}$, and locomotor activity counts were cumulated over 5-min intervals for the next $2 \mathrm{~h}$. Stereotyped behavior was rated during 45-s observation periods at 10 and $20 \mathrm{~min}$ following the injection, and every $20 \mathrm{~min}$ thereafter for $2 \mathrm{~h}$, by an observer blind to group membership. On AMPH treatment days when behavior was not monitored (treatment days 6,8 , and 9) the animals were immediately replaced into their home cage following the injection.

Three additional groups were included to address the role of drug-environment conditioning in the sensitization of locomotion and stereotypy ${ }^{64,72}$. Each of these control groups consisted of intact female $(n=10$ or 15$)$ and GDX male ( $n=10$ or 15$)$ rats, because it was hypothesized that: (1) intact and GDX females would not differ in their behavioral response to repeated AMPH treatment; and (2) these groups would show robust behavioral sensitization. A group of 'saline-control' (S) animals were treated exactly as the experimental animals described above, except they received injections of saline in place of AMPH for the first 9 days of drug administration, and $2.0 \mathrm{mg} / \mathrm{kg}$ AMPH on the tenth day. A 'pseudoconditioned' (Ps) group received the same AMPH treatment as described for the experimental animals, but did not receive AMPH in the test environment. On the 1st, 2nd, 3rd, 4th and 7 th test days the pseudoconditioned animals received saline in the activity monitors and $2.6 \mathrm{mg} / \mathrm{kg}$ AMPH just prior to being placed back in their home cages. On the tenth day, these animals received $2.0 \mathrm{mg} / \mathrm{kg}$ AMPH in the test 
cage. Thus, pseudoconditioned rats received the first 9 injections of AMPH in their home cages and only the tenth injection (challenge) in the test cage. Finally, 'non-handled-control' (NH) animals were left undisturbed in their home cages until the 10th test day, at which time they also received the challenge dose of AMPH $(2.0 \mathrm{mg} / \mathrm{kg})$ in the test cages. Locomotion and stereotypy were recorded as described for the experimental animals.

\section{Neurochemical procedures and methods}

Eight to 9 days following the last AMPH treatment, all experimental animals, and additional male and female rats (intact and GDX; $n=10 /$ treatment condition) that were either pretreated with saline (one injection every 3 days for a total of 10 injections) or non-handled, were killed by decapitation. The brains were rapidly removed ( $<40 \mathrm{~s})$ and dissected in ice-cold saline. The frontal cortex, nucleus accumbens and striatum were removed using a procedure similar to that described by Heffner et al. ${ }^{25}$, but with the following modifications. (1) The frontal cortex included only the medial tissue anterior to the genu of the corpus callosum; and (2) the nucleus accumbens and striatum were removed using $2 \mathrm{~mm}$ and $3 \mathrm{~mm}$ diameter micropunches, respectively. The tissue was immediately weighed and placed into tubes containing either $250 \mu \mathrm{l}$ (frontal cortex, nucleus accumbens), or $300 \mu \mathrm{l}$ (striatum) of $0.05 \mathrm{~N}$ perchloric acid, with dihydroxybenzylamine ( $2 \mathrm{ng} / 10 \mu \mathrm{l}$ and $4 \mathrm{ng} / 10 \mu \mathrm{l}$, respectively) added as an internal standard. The tissue samples were homogenized and centrifuged at $5000 \mathrm{~g}$ for $45 \mathrm{~min}$ at $2-4{ }^{\circ} \mathrm{C}$. The supernatant was then filtered using $0.2 \mu \mathrm{m}$ regenerated cellulose membrane filters and stored in vials at $-20^{\circ} \mathrm{C}$.

Tissue concentrations of dopamine (DA), 3,4dihydroxyphenylacetic acid (DOPAC), homovanillic acid (HVA), 5-hydroxytryptamine (5-HT; serotonin), and 5-hydroxyindoleacetic acid (5-HIAA) were assayed by high-performance liquid chromatography (HPLC) with electrochemical detection. Briefly, the HPLC system employed a Brownlee MPLC reverse phase C-18 column and an LC-4 electrochemical detector with a glassy carbon electrode (Bioanalytical
Systems). The detector potential was set at $+0.74 \mathrm{~V}$ against an $\mathrm{Ag} / \mathrm{AgCl}$ reference electrode. The mobile phase was a citric acid- $\mathrm{NaHPO}_{4}$ solution (pH 3.35) containing $25-30 \mathrm{mg} / \mathrm{l}$ octyl sulfonate and $8-10 \%$ methanol. Concentrations of each neurochemical were standardized across assays.

\section{Data analysis}

Non-parametric statistical techniques were used to analyze the stereotypy rating scores, including Profile analyses ${ }^{49}$ and Mann-Whitney $U$-tests for independent a priori comparisons. Locomotor scores and the neurochemical data were analyzed using parametric statistics that included one- or two-way analyses of variance for repeated measures, and the Student's $t$-test for individual a priori comparisons. All comparisons were based on two-tailed probabilities, unless otherwise noted. The $F$-values for group and interaction effects are indicated by $F g$ and $F 1$, respectively. Separate statistical analyses were conducted on the stereotypy scores obtained over test sessions $1-7$, versus those obtained during the 10th session, because of the difference between the sensitizing and challenge doses of AMPH.

\section{Results}

Stereotyped behavior: response to the first injection

The first injection of AMPH produced greater overall stereotypy in intact females, GDX females and GDX males than in intact males (Fig. 1A: $U=34, P=0.001 ; U=68, P=0.06 ; U=67$, $P=0.058$, respectively). The former 3 groups did not differ from each other. For stereotyped sniffing behavior (Fig. 1C), the comparison with intact males was significant for intact females ( $U=38, P=0.002)$, but not for GDX females $(U=86.5, P=0.3)$ or GDX males $(U=88$, $P=0.3$ ). Most animals did not show repetitive head and limb movements following the first injection of AMPH (Fig. 1B).

\section{Test sessions $1-7$}

Over the first 7 treatment days the repeated intermittent administration of AMPH produced a progressive increase in stereotyped behavior, including repetitive head and limb movements and 


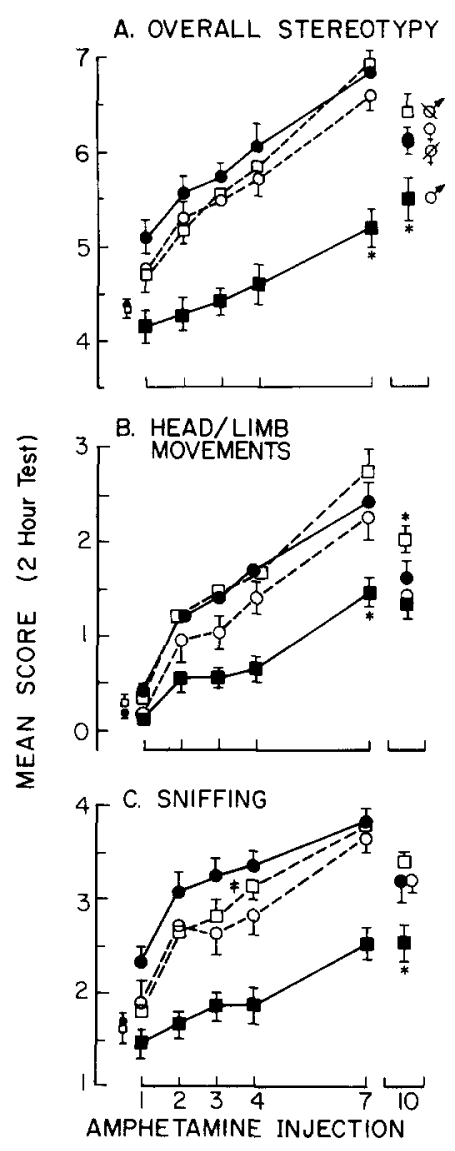

Fig. 1. The effects of gonadectomy (GDX) on the sensitization of amphetamine (AMPH)-induced stereotyped behavior (panel A: overall stereotypy; panel B: repetitive head and limb movements; panel C: stereotyped sniffing). The points represent the mean $( \pm$ S.E.M.) stereotypy scores cumulated over each 2-h test session. Intact male rats (solid squares) received $3.0 \mathrm{mg} / \mathrm{kg}$ AMPH on all test sessions. Intact females (solid circles), GDX females (open circles) and GDX males (open squares) received $2.6 \mathrm{mg} / \mathrm{kg} \mathrm{AMPH}$ during the first 9 days of AMPH treatment (test sessions $1,2,3,4$ and 7 are shown), but on the 10 th session received a lower challenge dose of AMPH $(2.0 \mathrm{mg} / \mathrm{kg}$; see Methods for rationale). A single acute injection of the challenge dose of AMPH did not behaviorally distinguish independent groups of intact female or GDX male rats from intact male rats (see small symbols at far left of each panel). * Significant interaction terms, differs from all other groups, $P<0.05$; ${ }^{\ddagger}$ Interaction effect, differs from intact males, $P=0.017$ (see text for details). Note that intact females, GDX females and GDX males show more robust sensitization than intact males.

sniffing, in all 4 groups (effect of test session, all $P$ 's $<0.001$ ). Most animals did not show stereotyped licking or biting with the doses used here.

To determine if endogenous gonadal hormones influenced the sensitization of stereotyped be- haviors, intact male and female rats were compared with GDX rats. Fig. 1A illustrates that GDX males showed a greater enhancement in overall stereotypy than intact males, as indicated by a significant group $\times$ test session interaction (profile analysis: $F \mathbf{1}=3.66, P=0.018$ ). In female rats, however, there was no significant effect of gonadectomy on the sensitization of overall stereotypy $\left(F \mathrm{~g}=1.7, P=0.2 ; F_{1}=0.3\right)$. Because intact and GDX females did not differ, these groups were pooled to test for sex differences in the sensitization of overall stereotyped behavior. Females showed a greater enhancement in overall stereotypy than intact males (i.e. the profiles are not parallel, $F 1=2.84, P=0.036$ ), but did not differ from GDX males $(F \mathrm{~g}=1.09, P=0.38$; $F \mathbf{i}=0.3$ ).

There were similar differences in the sensitization of repetitive head and limb movements (Fig. 1B). A profile analysis over test sessions 1-7 revealed no significant differences between intact and GDX female rats $(F \mathrm{~g}=1.39, P=0.3$; $F i=0.3$ ), and therefore their data were pooled. As illustrated in Fig. 1B, both female and GDX male rats showed a greater enhancement in repetitive head and limb movements than did intact male rats $\left(F 1=3.66, \quad P=0.012 ; \quad F_{1}=4.99\right.$, $P=0.004$, respectively). Again, female and GDX male animals did not differ from each other $\left(F \mathrm{~g}=0.7 ; F_{1}=1.23, P=0.3\right)$.

Fig. 1C illustrates that GDX males also showed more robust sensitization of stereotyped sniffing than did intact males $(F \mathrm{i}=3.67$, $P=0.017)$. There was a non-significant trend for intact females to have greater stereotyped sniffing scores than GDX females $(F \mathrm{~g}=3.26, P=0.08)$, and therefore the data for the female groups were not pooled for the comparison with males. Both intact and GDX female rats showed more sniffing behavior than intact males (group effects: $F$ 's $=39.5$ and $13.8, P<0.001$ ), but the interaction terms were not significant. The two female groups did not differ significantly from GDX males.

\section{Challenge test (test session 10)}

Fig. 1A (far right) shows that even during the challenge test, when intact females, GDX females 
and GDX males received $2.0 \mathrm{mg} / \mathrm{kg}$ and intact males $3.0 \mathrm{mg} / \mathrm{kg}$, the former 3 groups showed significantly greater overall stereotyped behavior than intact males $(U=65, P=0.048 ; U=65.5$, $P=0.05 ; U=50.5, P=0.01$, respectively), but did not differ from each other. Likewise, during the challenge test stereotyped sniffing behavior (Fig. 1C) was significantly greater in these 3 groups than in intact males (intact females: $U=64.5, P=0.046$; GDX females: $U=51.5$, $P=0.011$; GDX males: $U=34.5, P=0.001$ ). A single acute injection of this dose did not distinguish the stereotyped behavior of intact female, GDX male and intact male rats (small symbols to the far left of Fig. 1A-C).

Analysis of repetitive head and limb movements during the challenge test revealed a different pattern of effects than did analysis of overall stereotypy or stereotyped sniffing (Fig. 1B). It might not have been expected that the lower challenge injection of AMPH would come to distinguish head and limb movements in the 4 groups of animals, because there were no initial differences among the 4 groups (see above). However, even when challenged with $2.0 \mathrm{mg} / \mathrm{kg}$ GDX males had significantly higher repetitive head and limb movement scores than did intact males $(U=64, P=0.044)$, intact females $(U=65$, $P=0.048), \quad$ or GDX females $(U=55.5$, $P=0.017)$, and these latter 3 groups did not differ from each other (all $P$ 's $>0.39$ ).

\section{Influence of conditioning variables}

To determine if repeatedly pairing AMPH with the test environment (activity monitors) influenced the sensitization of stereotypy, the "sensitized' groups of intact female and GDX male rats described above were each compared with a pseudoconditioned control group that previously received saline in the testing environment, and AMPH in their home cages. On the 10th day of AMPH treatment, both groups received the challenge dose in the test cages. Fig. 2 shows that there was no difference between rats that received AMPH in the test cage (A) and pseudoconditioned (Ps) animals in overall stereotypy, repetitive head and limb movements, or sniffing behavior.

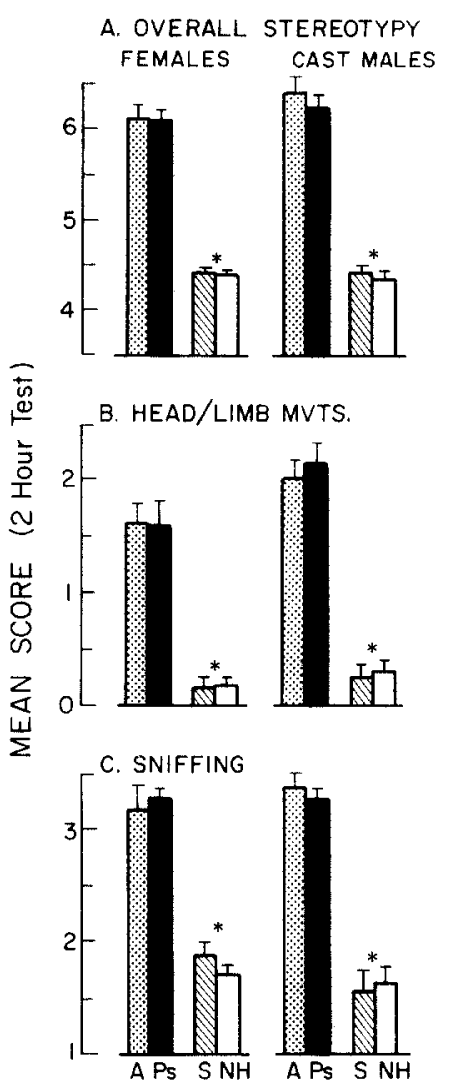

Fig. 2. The mean ( \pm S.E.M.) stereotypy scores cumulated over a 2-h test session following the administration of $2.0 \mathrm{mg} / \mathrm{kg} \mathrm{AMPH}$ to groups of intact female and castrated (CAST) male rats that differed in their previous history of drug-test environment pairing. AMPH-pretreated animals (A; $n=15$ /group) are the same animals shown in Fig. 1, and they received 5 previous injections of $2.6 \mathrm{mg} / \mathrm{kg} \mathrm{AMPH}$ in the test chambers. Pseudoconditioned rats (Ps; $n=10 /$ group) received the same treatment as AMPH-pretreated animals, except they received saline in the test environment and AMPH two h later in their home cage (i.e. AMPH was not paired with the test environment). Saline-control animals (S; $n=10 /$ group) received repeated injections of saline in the test environment, but no AMPH. Non-handled control animals (NH; $n=15 /$ group) received no previous experience in the test environment, and no injections. The data illustrated were obtained when all animals received a challenge injection of $2.0 \mathrm{mg} / \mathrm{kg}$ of AMPH on the $10 \mathrm{th}$ test session. Note that there was no difference between $A$ and $P$ s animals, or $S$ and NH animals on any of the stereotypy rating scales. However, the 'sensitized' animals (A plus Ps) had significantly greater stereotypy scores than control (S plus NH) animals $\left(^{*}=P<0.001\right)$.

Fig. 2 also illustrates that previous experience in the testing environment in association with the injection procedure did not contribute to the development of sensitization. A saline control (S) 
group did not differ from non-handled control (NH) animals in their response to an acute injection of the challenge dose of AMPH ( $P$ 's $>0.35$ ). However, when the pooled data for sensitized and pseudoconditioned animals are compared with the pooled data of saline- and non-handled-control animals (Fig. 2), it is clear that pretreatment with AMPH in either female or GDX male animals produced a robust enhancement in overall stereotyped behavior, repetitive movements of the head and limbs, and sniffing behavior (all $P$-values $<0.001)$. Finally, an injection of saline given 3 days following the last test with AMPH did not produce stereotyped behavior.

\section{Locomotor activity (crossovers)}

\section{Effects of the first injection of AMPH}

Fig. 3 (panel A) illustrates the effects of gonadectomy on the time course of locomotor activity (i.e. movements from one end of the cage to the other, or crossovers) in both male (column 1) and female (column 2) rats following the first injection of AMPH. Panel G illustrates the effects of a subsequent injection of saline. The first injection of AMPH enhanced locomotion in all 4 groups of animals (compare panels $A$ and $\mathrm{G}$ ), but the 4 groups did not differ from each other on this measure (two-way ANOVA's comparing each group with each other group).

\section{Effects of repeated exposure to AMPH}

With subsequent injections of AMPH (Fig. 3, panels B-E) a different pattern of behavior emerged. Compared with the response to the first AMPH injection, the time course of locomotion following the second injection showed an intermediate phase during which there was a significant reduction in locomotor activity (test session $\times$ time interaction: all $P$ 's $<0.006$ ). Direct observation of the animals confirmed that this reduction was due to the presence of intermittent episodes of stereotyped behavior (i.e. stereotypy phase). Following the 3rd, 4th and 7th injections (panels $\mathrm{C}-\mathrm{E}$ ), this multiphasic pattern of behavior, consisting of an early and late period of enhanced locomotion and an intermediate period of continuous stereotypy during which locomotion was greatly reduced, became progressively more pronounced.

With repeated AMPH injections all 4 groups of animals developed this multiphasic pattern of behavior to some extent, but there were also significant group differences. Panel 1C (Fig. 3) illustrates that following the third injection of AMPH both intact and GDX males showed a stereotypy phase of reduced locomotion, but the stereotypy phase was longer-lasting in GDX males than in intact males, as indicated by a significant interaction. Individual comparisons comparing the number of crossovers made during each 5-min interval in intact and GDX males confirmed that the interaction was due entirely to the greater decrease in the number of crossovers made by GDX males during the $60-90 \mathrm{~min}$ period following the AMPH injection. By the seventh AMPH injection, GDX males not only had a longer-lasting stereotypy phase than intact males, but showed more focused stereotyped behavior than intact males, as reflected by the greater reduction in activity during the entire intermediate period (see panel 1E). That the intact males were more hyperactive during the test session is also indicated by an average overall stereotypy rating of about 5 ('hyperactive'), versus an average rating of close to 7 ('fast patterned stereotypy') for GDX males (Fig. 1).

In contrast, intact and GDX female rats (column 2, Fig. 3) showed an almost identical change in their locomotor response across repeated test sessions (all ANOVA's non-significant). The data for the two female groups were pooled to test for sex differences in the locomotor response to repeated AMPH injections. When compared to intact males, females showed both a more intense and longer-lasting stereotypy phase of reduced locomotion following the 3rd, 4th and 7th AMPH injections (columns 1 and 2, panels $\mathrm{C}-\mathrm{E}$ ), as reflected by significant interaction effects $(F$ 's $=1.79-2.42, \quad P$ 's $<0.01-$ 0.001 ); also compare the stereotypy ratings.

In summary, analysis of the change in locomotor activity between the 1st and 7th injections of AMPH yielded the same pattern of group differences as found for stereotypy rating scores. 


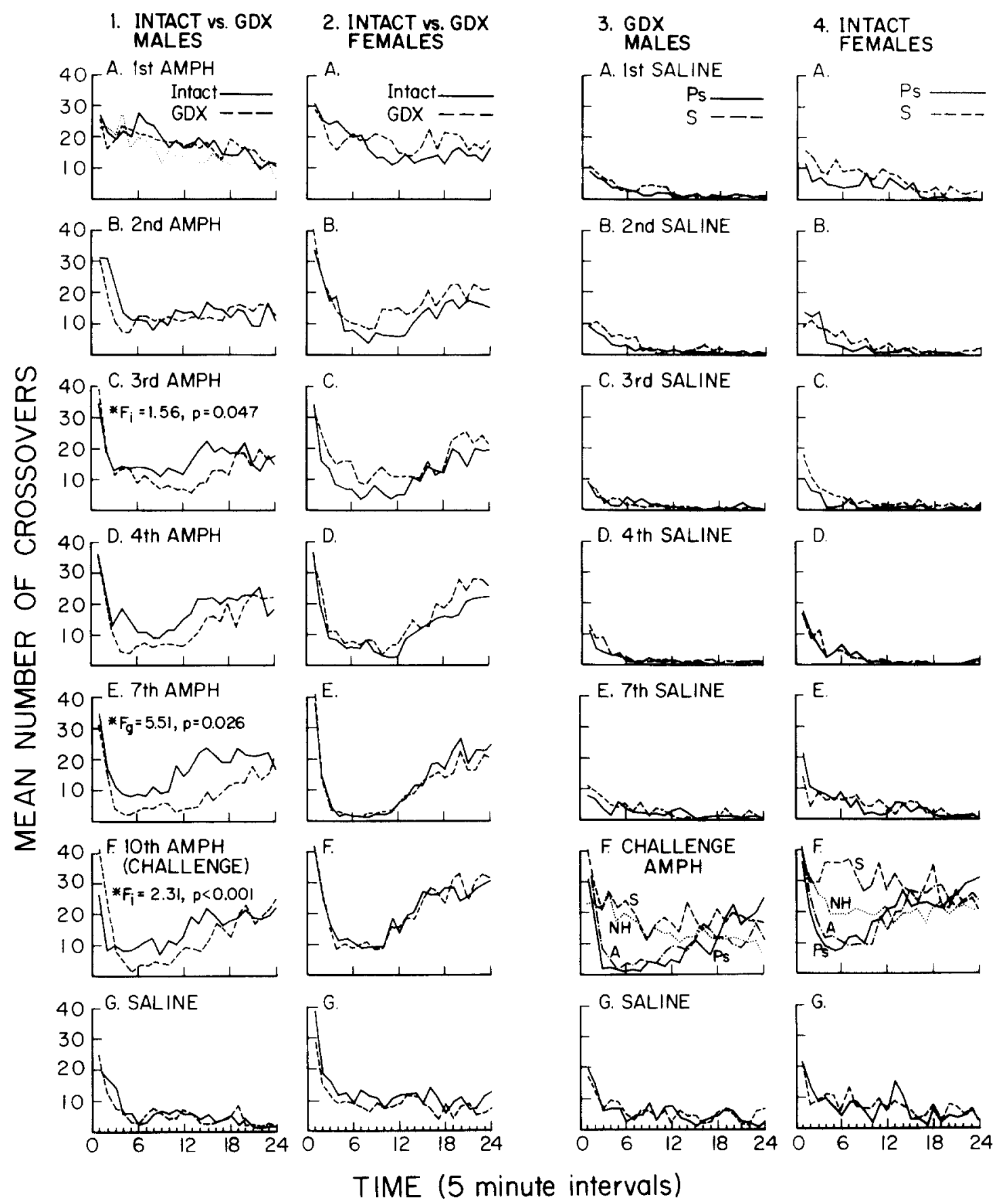

Fig. 3. Columns 1-2: the average number of photocell interruptions (crossovers) during each of 24 five-min intervals following the administration of AMPH or saline, in intact and gonadectomized (GDX) male and female rats. Panels A-F show the number of crossovers made following the 1st, 2nd, 3rd, 4th and 10th injections of AMPH, respectively. Panel G shows the number of crossovers made following an injection of saline, which was given 3-4 days following the last day of AMPH treatment. Panel A also shows the locomotor response in a group of non-handled GDX male rats that received only one acute injection of the lower challenge dose of AMPH (small dotted line; also shown in column 3, panel F). Note that this latter group did not differ from intact males given their first injection of AMPH. The groups consist of the same animals as described in Fig. 1 (also see text). Significant differences between intact and GDX animals are indicated by an asterisk. The $F$-values and probability values are also shown $(F \mathrm{~g}=$ group effect; $F \mathbf{i}=$ interaction effect). Note that GDX males did not differ from intact males following the first injection of AMPH, but with repeated AMPH treatment they came to do so. The GDX females did not differ from intact females 
Intact female, GDX female and GDX male rats all showed more robust changes in behavior with repeated exposure to AMPH than did intact males, and the former 3 groups did not differ from each other.

\section{Challenge test}

There were similar effects of gonadectomy on locomotor activity during the 10th AMPH test, at which time intact female, GDX female and GDX male rats received the lower challenge dose of AMPH. Again, intact and GDX males differed, as reflected by a significant group $\times$ time interaction (Fig. 3, panel 1F). Individual comparisons at each 5-min interval showed that GDX males had a pre-stereotypy phase of increased locomotion (first 5-10 min following AMPH) and a stereotypy phase of decreased locomotion that were greater than in intact males. However, the post-stereotypy phase of hyperactivity was comparable in the two male groups. In addition, it should be noted that an independent group of GDX males given a single acute injection of $2.0 \mathrm{mg} / \mathrm{kg}$ (challenge dose) did not differ significantly from intact males on test session 1 (small dotted line in panel 1A). In contrast, intact and GDX females showed an almost identical pattern of locomotion during the challenge test (all $F$ 's $<0.4$ ).

\section{Influence of conditioning variables}

The effects of a challenge injection of AMPH on pseudoconditioned, saline-pretreated and non-handled control rats are shown in Fig. 3 (columns 3 and 4, panel F). The data for sensitized animals shown in columns 1 and 2 are reproduced in columns 3 and 4 (group A) respectively, for ease of comparison.
It is clear from Fig. 3 that pseudoconditioned (Ps) animals did not differ from sensitized (A) animals during the challenge test (GDX males: $F \mathrm{~g}=2.91, P=0.1 ; F \mathbf{1}=1.26, P=0.2 ;$ Intact females: $F$ 's $<1.0$ ). It was not necessary, therefore, to pair AMPH administration with the test environment to produce the changes in locomotor activity described above. The pseudoconditioned and the normally sensitized groups (A) differed from both saline-pretreated and non-handled control animals ( $F$ i's $=3.04-10.75$, all $P<$ 0.001). Saline-pretreated GDX males did not differ from non-handled GDX males (panel 3G), but saline-pretreated females did show more locomotion than non-handled females $(F 1=1.63$, $P=0.034$ ).

Finally, there was no effect of GDX in males or females on the locomotor response to an injection of saline (Fig. 3, panels $1 \mathrm{G}$ and $2 \mathrm{G}$ ), although females were more active than males $(P<0.001)$. More importantly, the saline 'challenge' did not produce an increase in locomotion comparable to that produced by AMPH. Direct observation of the rats confirmed that the absence of locomotion following saline was not due to the presence of stereotypy, as no animal received an overall stereotypy rating greater than 4 ('normal, alert, active') during the 2 -h test session.

\section{Neurochemical results}

Dopaminergic indices. Table I shows the concentration of DA, DOPAC and HVA in the striatum, nucleus accumbens and medial frontal cortex for all 4 groups. There were no differences between saline-pretreated and non-handled control animals, and therefore these two groups were pooled (control) for comparison with AMPHpretreated animals. Intact female, GDX female,

at any point in time. Columns 3-4: the effects of drug-environment conditioning on changes in the time course of locomotor activity (mean number of crossovers per 24 five-min intervals) in intact female and GDX male rats. During the 1st, 2 nd, 3rd, 4 th and 7th day of drug treatment pseudoconditioned (Ps) and saline-pretreated (S) animals received saline in the test cage, and the number of crossovers for each of 24 five-min intervals are shown in Panels A-E. The pseudoconditioned animals received AMPH $(2.6 \mathrm{mg} / \mathrm{kg})$ in their home cage following each of these test sessions, and during the 5 th, 6th, 8th and 9th days of drug treatment. On the 10th treatment day, these groups, and a group of non-handled control animals (NH), were administered a challenge injection of AMPH $(2.0 \mathrm{mg} / \mathrm{kg}$ ) in the test cage (panel F). For purposes of comparison, panel $\mathrm{F}$ also shows the data for AMPH-pretreated intact females and GDX males displayed in columns 1-2, panel F. Panel G illustrates the effects of a subsequent injection of saline administered to pseudoconditioned and saline-pretreated animals 3-4 days following the AMPH challenge test. See the text for a description of the results. 


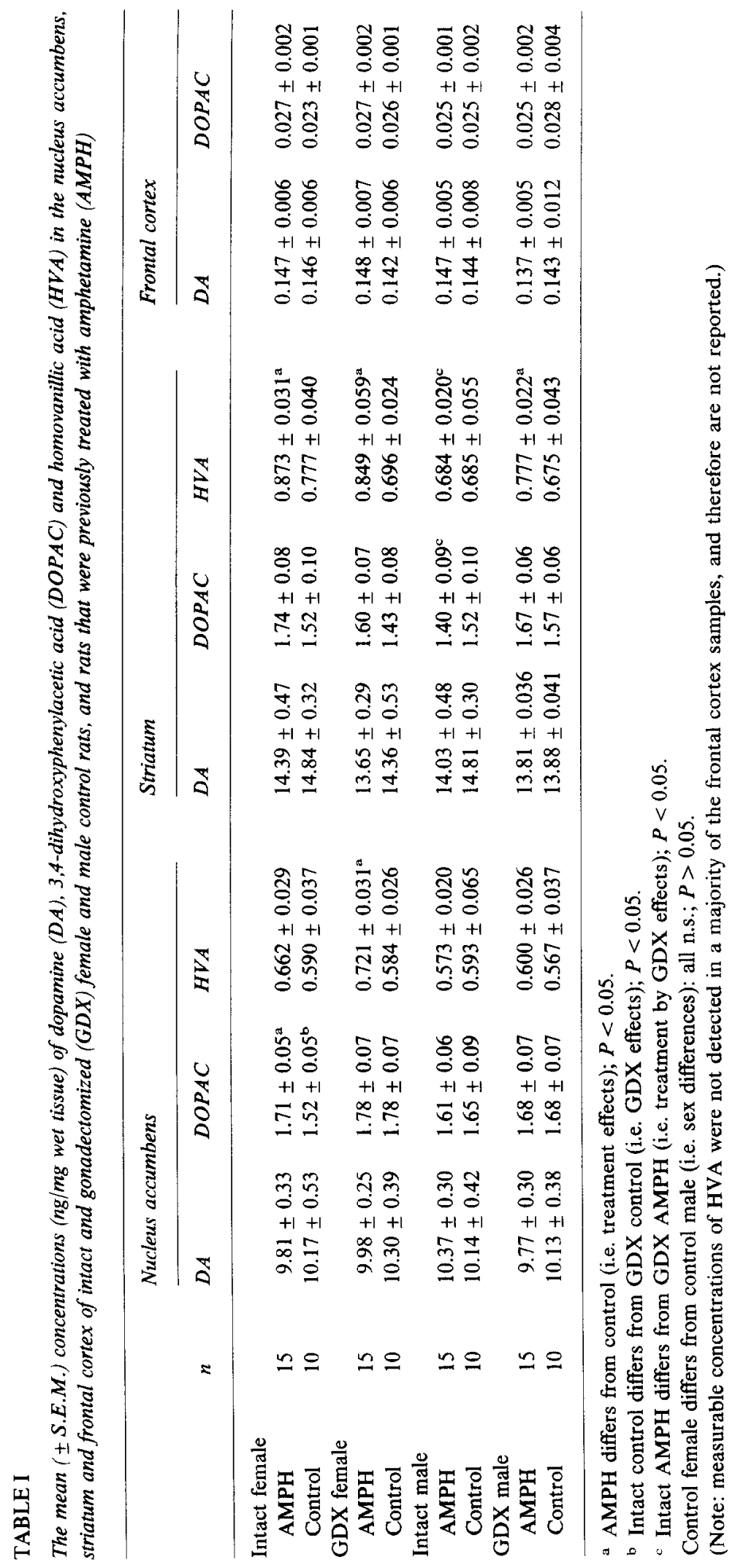


striatal HVA concentrations, relative to control animals (Table I). Although the concentration of HVA in the nucleus accumbens was also elevated in these groups, the difference was statistically significant only for GDX females $(t=3.08$, $P=0.005)$. In contrast, AMPH pretreatment had no measurable effect on striatal or nucleus accumbens HVA concentrations in intact male rats $(t=0.03-0.35)$. Consistent with previous reports (ref. 59 for review), there were no changes in basal concentration of DA or DOPAC in any brain region, except for a significant enhancement in nucleus accumbens DOPAC concentrations in AMPH-pretreated intact females (Table I).

The ratio of DA metabolite to DA concentrations is thought to be a sensitive index of DA metabolism under some experimental conditions $^{8,40,71}$, and therefore DOPAC/DA and HVA/DA ratios were calculated to further examine the effects of AMPH pretreatment on DA metabolism. There were no significant differences in DOPAC/DA or HVA/DA ratios between saline-pretreated and non-handled control animals in any brain region, except the striatal DOPAC/DA ratio tended to be higher in salinepretreated than non-handled GDX male rats (Fig. $4 ; t=1.95, P=0.087$ ). Therefore, except in this latter instance, data for the two control groups were pooled for comparison with AMPHpretreated animals. Fig. 4 illustrates the effects of repeated AMPH treatment on striatal DA metabolism, as indicated by metabolite/DA ratios. AMPH pretreatment significantly increased striatal DA metabolism in intact female, GDX female and GDX male rats, as estimated by DOPAC/DA ratios (Fig. 4A: intact females: $t=2.08, P=0.049$; GDX females: $t=2.44$, $P=0.023$; GDX males: A vs $\mathrm{NH}, t=2.19$, $P=0.04$, although A vs $\mathrm{S}, t=0.31$ ), and HVA/DA ratios (Fig. 4B: $t=2.33, P=0.029$; $t=2.44, P=0.023 ; t=2.98, P=0.007$, respectively). In contrast, AMPH pretreatment had no effect on striatal DA metabolism in intact male rats (Fig. 4; DOPAC/DA: $t=0.3$; HVA/DA: $t=0.8$ ).

Repeated AMPH treatment had no significant effect on basal DA metabolism in the nucleus accumbens or frontal cortex, except nucleus

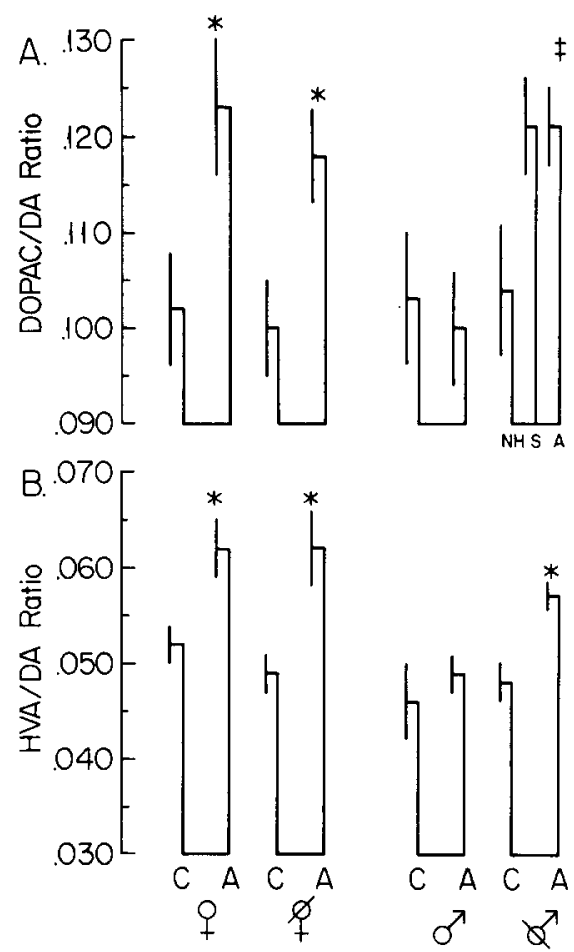

Fig. 4. The mean ( \pm S.E.M.) striatal DOPAC/DA and HVA/DA ratios for AMPH-pretreated (A) and control (C) intact female, GDX female, intact male and GDX male rats (from the left). Data from saline-pretreated and non-handled animals were pooled to form the control groups. The DOPAC/DA ratios are shown separately in saline-pretreated (S) and non-handled (NH) GDX males, because only in this group was there a tendency for these two control groups to differ $(t=1.95, P=0.087)$. Striatal DOPAC/DA and HVA/DA ratios were significantly elevated in the AMPHpretreated intact females, GDX females and GDX males $\left(^{*}=\right.$ significantly different from the control group, $P<0.05$; ¥ differs from non-handled controls, $P=0.04$; two-tailed Student's $t$-tests). AMPH pretreatment had no effect on the DA metabolite to DA ratios in intact males. Group n's given in Table I. DA, dopamine; DOPAC, dihydroxyphenylacetic acid; HVA, homovanillic acid.

accumbens HVA/DA ratios were significantly enhanced in AMPH-pretreated GDX female rats $(0.072 \pm 0.003$ vs $0.057 \pm 0.002 ; \quad t=3.72$, $P=0.001)$.

Serotoninergic indices. The concentrations of serotonin (5-HT), its metabolite, 5-HIAA, and 5-HIAA/5-HT ratios in the nucleus accumbens, striatum and frontal cortex of AMPH-pretreated and control animals were determined (data not shown). The ratio of 5-HIAA to 5-HT has been reported to be a good index of serotonin utiliand GDX male rats that were pretreated with AMPH showed a significant increase in the 
zation $^{68}$. There was no influence of saline-pretreatment on any of the neurochemical measures, and therefore the data for saline-pretreated and non-handled control animals were pooled. There were no differences between AMPH-pretreated and control animals on any measure of serotonin activity, with one exception. AMPH-pretreated GDX male rats had a significantly elevated striatal 5-HIAA/5-HT ratio $(t=2.55, P=0.018)$.

Although there were no statistical differences between AMPH-pretreated and control animals when each of the 4 groups were compared separately, AMPH-pretreated intact females, GDX females and GDX males, (i.e. the three groups showing the most robust behavioral sensitization) consistently had higher 5-HIAA concentrations and 5-HIAA/5-HT ratios than controls. When these 3 groups were pooled, the difference between AMPH-pretreated and control animals was statistically significant for both measures of serotonin activity in the striatum (5-HIAA: $t=2.02, \quad P=0.047 ;$ 5-HIAA/5-HT : $t=3.06$, $P=0.003$ ) and nucleus accumbens (5-HIAA: $t=2.67, \quad P=0.009 ;$ 5-HIAA/5-HT: $t=2.06$, $P=0.043 ;$ all $\mathrm{df}=73$ ).

\section{Subgroup analyses}

The animals in each group were subdivided into subgroups consisting of: (1) animals which showed a strong multiphasic pattern of behavior following the last injection of AMPH, as described by Segal and Mandell ${ }^{67}$; i.e. an initial period of enhanced locomotion, followed by a period in which locomotion was absent (the stereotypy phase) and a post-stereotypy period of heightened locomotion; and (2) animals that did not show intense focused stereotypy, as indicated by a period in which locomotion was completely absent. For convenience, the former groups will be referred to as 'low activity groups' (LO) and the latter groups as 'high activity groups' (HI). It is presumed that the HI groups (least focused stereotypy) are less sensitized than the LO groups (most focused stereotypy). Only after animals were placed into one of these subgroups was the neurochemical data re-examined.

Fig. 5 (panels A-D) shows the activity counts for the two subgroups of intact females (Fig. 5A),
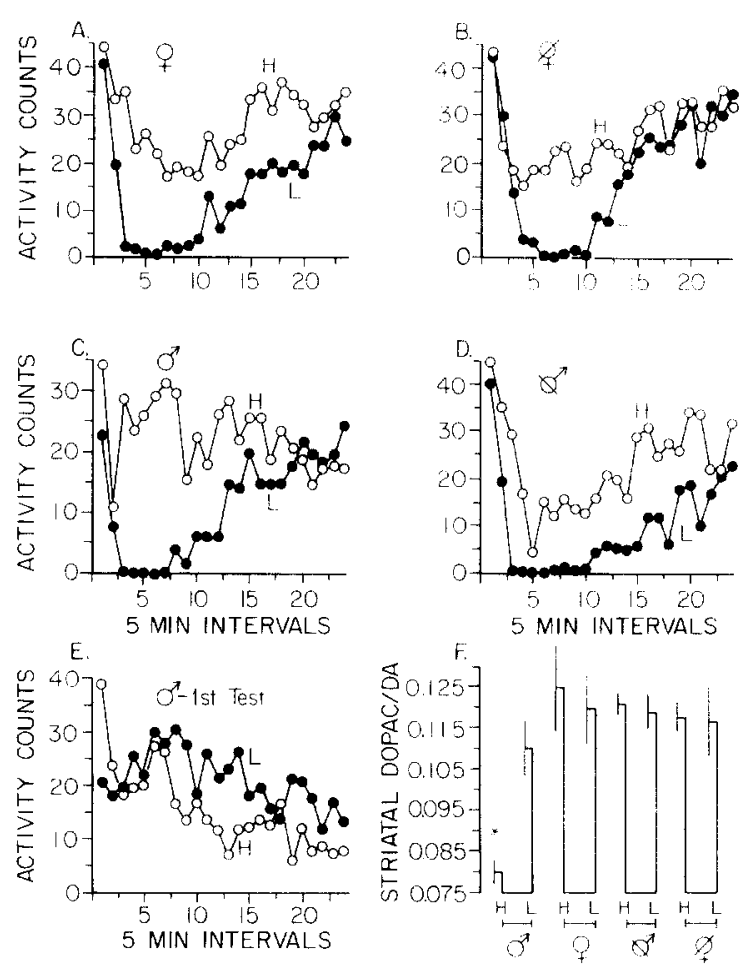

Fig. 5. The mean locomotor activity counts (photocell beam disruptions) over 24 five-min intervals following the last injection of amphetamine (10th test session) in intact female (panel A), gonadectomized (GDX) female (panel B), intact male (panel C) and GDX male (panel D) rats. These groups were subdivided into subgroups showing relatively low levels of locomotor activity ( $\mathrm{L}$, focused stereotypy) and those showing relatively high levels of locomotor activity $(H$, less focused stereotypy; see text). Panel E shows the locomotor activity for the $\mathrm{H}$ and $\mathrm{L}$ intact male subgroups following the first injection of amphetamine. Note that these two subgroups did not differ in their behavioral response to amphetamine following their initial exposure to the drug. Panel $F$ shows the mean ( \pm S.E.M.) striatal DOPAC/DA ratios for each of the high activity $(\mathrm{H})$ and low activity $(\mathrm{L})$ subgroups. Note that there is a significant difference $\left({ }^{*}=P<0.01\right)$ between the intact male $\mathrm{H}$ and $\mathrm{L}$ subgroups, but no differences between any of the other subgroups. Group $n$ 's: Male H(5), L(10); GDX male H(4), L(11); Female H(7), L(8); GDX female $\mathrm{H}(7), \mathrm{L}(8)$.

GDX females (Fig. 5B), intact males (Fig. 5C) and GDX males (Fig. 5D) during the last test session. Of course, the $\mathrm{HI}$ and LO subgroups are all highly statistically different, because they were selected to be maximally different. It is interesting, however, that for intact females, GDX females and GDX males even the HI activity subgroups showed some reduction in locomotion during the 
period when the LO groups show the most focused stereotypy (i.e. no locomotion). In contrast, $\mathrm{HI}$ activity intact male animals did not show any comparable reduction in locomotion (Fig. 5C). It appears that intact males were more clearly subdivisible into two very distinct subgroups on the basis of this behavioral measure than were intact females, GDX females or GDX males. Fig. 5 (panel E) also shows that the intact male subgroups did not differ in their behavioral response to the first injection of AMPH (nor did any of the other subgroups), supporting the notion that LO activity animals were more highly sensitized than HI activity animals. That is, only after repeated exposure to AMPH did the two groups differentiate.

Striatal DOPAC/DA ratios for $\mathrm{HI}$ and LO activity intact males, intact females, GDX males and GDX females are shown in Fig. 5 (panel F). It should be kept in mind that the neurochemical data were obtained 8-9 days after the last injection of AMPH, and when animals were in a non-drugged state. It can be seen in Fig. $5 \mathrm{~F}$ that for intact males the LO and HI activity subgroups were neurochemically distinct, with the former group having significantly higher DOPAC/DA ratios $(t=2.84, P=0.014)$. In contrast, there was no difference in striatal DOPAC/DA ratios between LO and $\mathrm{HI}$ activity subgroups for intact females, GDX females or GDX males. There were no significant differences between any subgroups in nucleus accumbens or frontal cortex DOPAC/DA ratios.

EXPERIMENT 2: THE INFLUENCE OF ENDOGENOUS GONADAL HORMONES ON THE BEHAVIORAL SENSITIZATION PRODUCED BY REPEATED INTERMITTENT RESTRAINT STRESS

\section{Method}

Pilot studies were conducted with intact female rats to determine if repeated restraint stress $(2,4$ or 10 consecutive days for $3 \mathrm{~h}$ each day) would produce enduring changes in the locomotion or stereotypy produced by a subsequent injection of AMPH $(2.0,2.5$ or $5.0 \mathrm{mg} / \mathrm{kg})$. After establishing that behavioral changes were indeed produced with this 'cross-sensitization' paradigm (also see ref. 28), the influence of endogenous gonadal hormones on the development of sensitization to repeated restraint stress was studied.

Two weeks after GDX or a sham operation, male and female rats received one of three treatments: (1) 5 consecutive days of restraint stress ( $n=15 /$ group); (2) 15 consecutive days of restraint stress ( $n=15$ /group); or (3) no treatment ( $n=15$ /group). Restraint stress consisted of individually wrapping each rat in a cloth towel and then leaving it undisturbed in a lighted open area for $3 \mathrm{~h}$ each day. Animals in the no treatment control group were left undisturbed in their home cages. Ten days after the last restraint stress session all animals were tested for AMPHinduced stereotyped behavior, much as described above. Pilot studies showed that $3.5 \mathrm{mg} / \mathrm{kg}$ AMPH elicited a behavioral response that was maximally sensitive to the effects of previous restraint stress. Therefore, intact females, GDX females and GDX males all received $3.5 \mathrm{mg} / \mathrm{kg}$ $\mathrm{AMPH}$, and intact males received $4.0 \mathrm{mg} / \mathrm{kg}$ AMPH. Intact males received a higher dose for the reasons cited above ${ }^{7}$. Stereotyped behavior was rated during a 45-s observation period every $10 \mathrm{~min}$ following the injection, for $2.5 \mathrm{~h}$, by two observers unaware of the treatment conditions for individual animals.

\section{Results}

\section{Stereotyped behavior}

Fig. 6 (panels A-D) shows the overall stereotypy scores for each rating interval over the 2.5-h period following AMPH administration in previously restrained and control animals. Profile analyses $^{49}$ of the time course were conducted comparing each treatment group (5 or 15 days of restraint) with its respective control group ( 0 days restraint). Previously restrained intact female, GDX female and GDX male rats had significantly higher stereotypy scores over the 2.5-h test session than did their respective control groups (all main effects: 5 -day restraint groups: $F=4.73$, $P=0.038 ; \quad F=4.94, \quad P=0.035 ; \quad F=4.04$, $P=0.05 ; 15$-day restraint groups: $F=14.5$, $P<0.001 ; \quad F=13.0, \quad P<0.001 ; \quad F=8.51$, 

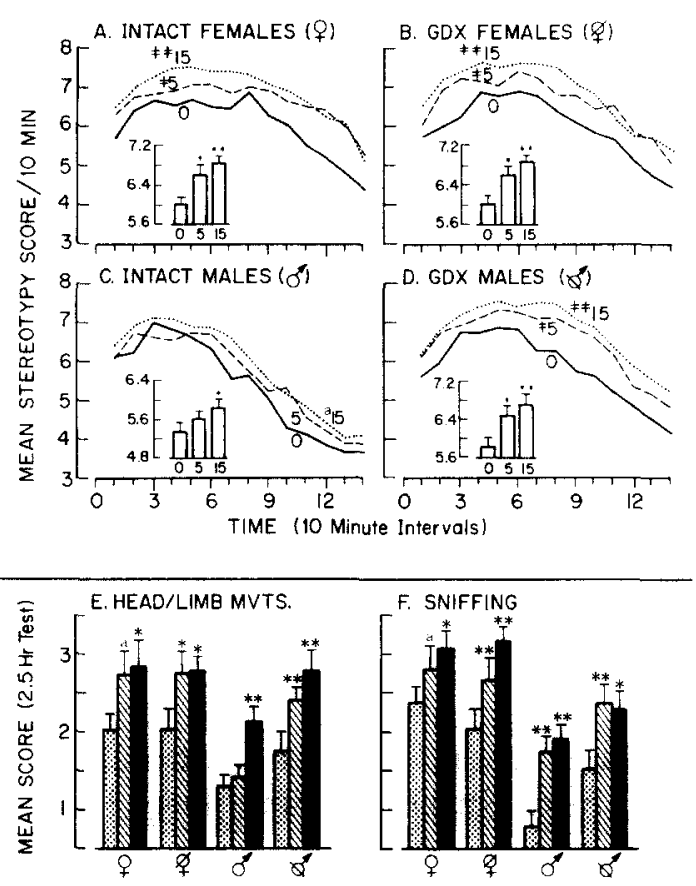

Fig. 6. The sensitization of amphetamine-induced stereotypy produced by repeated exposure to daily restraint stress. Panels A-D show the mean overall stereotypy scores for each of 14 ten-min intervals following an injection of amphetamine in animals that received either 5 or 15 daily sessions of restraint stress 10 days prior to the injection of AMPH, or animals that received no restraint stress (' 0 '; non-handled controls). The inserts in Panels A-D show the mean ( \pm S.E.M.) stereotypy scores cumulated over the entire 2.5-h test session in these same groups of animals. The restrained groups were each compared with their respective control group (profile analyses: ${ }^{a} P=0.07 ;{ }^{\ddagger} P<0.05$; ${ }^{\ddagger} P<0.01$; Mann-Whitney $U$-tests: ${ }^{*} P<0.05$; ${ }^{* *} P<0.01$ ). Panels $E$ and $F$ illustrate the effects of repeated restraint stress on the sensitization of AMPH-induced repetitive head and limb movements and stereotyped sniffing, respectively. The bars indicate the mean stereotypy scores cumulated over the 2.5-h test session, and the lines represent the S.E.M. Dotted bars, 0 days of restraint (controls); striped bars, 5 days of restraint; solid bars, 15 days of restraint. The restrained groups were each compared with their respective control group. (One-tailed Mann-Whitney $U$-tests: ${ }^{\mathrm{a}} P=0.06 ;{ }^{*} P<0.05 ;{ }^{* *} P<0.01$; see text for details.)

$P=0.007$, respectively). In contrast, overall stereotypy scores in intact male rats were not affected by 5 days of previous restraint $(F=0.9)$. Furthermore, after 15 daily restraint sessions there was only a non-significant tendency for elevated stereotypy scores in intact males $(F=3.56, P=0.07)$. One-tailed Mann-Whitney $U$-tests comparing the cumulative overall stereo- typy scores for the entire 2.5 -h test session showed exactly the same pattern of effects as the profile analyses (Fig. 6; insets on panels A-D).

The effects of prior restraint stress on repetitive head and limb movements produced by AMPH were similar as for overall stereotypy scores (Fig. 6E). Five restraint sessions enhanced AMPH-induced repetitive head and limb movements in intact females, GDX females and GDX males, relative to their respective control animals (one-tailed Mann-Whitney $U$-tests: $U=76$, $P=0.065 ; \quad U=71.5, \quad P=0.044 ; \quad U=54.5$, $P=0.008$ ), but was without effect in intact male rats $(U=91, P=0.2)$. However, 15 daily restraint sessions enhanced head and limb movements in all 4 groups, relative to their respective control groups (intact females: $U=66.5$, $P=0.028$; GDX females: $U=66, P=0.026$; intact males: $U=39, P=0.001$; GDX males: $U=48.5, P=0.004$; all one-tailed tests).

Analyses of stereotyped sniffing behavior revealed a different pattern of effects than did overall stereotypy or repetitive head and limb movements. Fig. 6F shows that both 5 and 15 days of previous restraint stress enhanced stereotyped sniffing scores in all groups (intact females: 5 days, $U=75.5, P=0.062 ; 15$ days, $U=56, \quad P=0.009$; GDX females: 5 days, $U=66, P=0.025 ; 15$ days, $U=36.5, P=0.001$; intact males: 5 days, $U=37.5, \quad P=0.001$; 15 days, $U=25.5, \quad P<0.001 ;$ GDX males: 5 days, $U=49.5, P=0.004 ; 15$ days, $U=62.5$, $P=0.019$; all one-tailed tests). Thus, for intact males stereotyped sniffing behavior was more sensitive to the effects of previous restraint stress than the other measures of stereotyped behavior. However, it should be noted that several of the intact female control rats received the maximum rating for sniffing (i.e. a score of 6) for the intervals during which stereotypy was most intense, suggesting a possible 'ceiling effect'.

Finally, stereotypy ratings made by the two observers were compared to determine inter-rater reliability. The observers' ratings were highly correlated for each of the stereotypy measures. The correlation coefficients for the cumulative 2.5-h rating scores for overall stereotypy, repetitive head and limb movements, and stereotyped 
sniffing were $+0.98,+0.97$ and 0.97 , respectively.

\section{DISCUSSION}

Three questions regarding the sensitization of stereotyped behavior, locomotion and brain monoamines were addressed. (1) Are sex differences in AMPH sensitization related to sex differences in circulating levels of gonadal hormones? (2) How are neural correlates of behavioral sensitization influenced by sex and/or gonadal hormones? (3) Do sex and/or gonadal hormones influence the sensitization produced by repeated restraint stress in a similar manner as they do sensitization to AMPH? Each of these issues will be discussed in turn.

\section{Effects of endogenous gonadal hormones on be- havioral sensitization to $A M P H$}

It was previously reported that female rats are more susceptible to behavioral sensitization than males ${ }^{14,15,55,61}$, and this sex difference was replicated here. In addition, it was found that sex differences in sensitization appear to be largely due to sex differences in the circulating levels of male gonadal hormones. In males removal of endogenous gonadal hormones by gonadectomy (GDX) produced a significant enhancement in the sensitization of overall stereotypy, stereotyped sniffing, stereotyped repetitive head and limb movements, and AMPH-induced locomotor activity (relative to intact males). In contrast, GDX did not affect behavioral sensitization in female rats. These results, and the results of previous studies in which rotational behavior was quantified $^{55,61}$, suggest that testicular secretions in adulthood retard the development of sensitization produced by repeated intermittent injections of AMPH.

It is interesting that in contrast to the effects reported here, ovarian, and not testicular hormones seem to modulate some of the acute effects of AMPH. For example, in female rats GDX attenuates AMPH-induced rotational behavior $^{5,13}$, and AMPH-stimulated striatal DA release in vitro ${ }^{6}$. However, GDX has no effect on either of these measures in males ${ }^{6,13}$. Therefore, the effects of gonadal hormones on the acute be- havioral and neurochemical response to AMPH may be very different to their effects on neuroplastic adaptations to repeated AMPH treatment.

Androgens affect AMPH metabolism ${ }^{7,34,46}$, and therefore, it is important to consider whether the effect of GDX on sensitization described here is due to pharmacokinetic differences between the groups. It is difficult to totally control for pharmacokinetic variables, but the available evidence suggests these cannot account for the present results, for the following reasons. (1) In this, and in previous studies ${ }^{1,15,55,61}$ the systemic dose of AMPH was titrated so that brain levels of AMPH would be equivalent in intact, as well as in GDX, males and females ${ }^{7}$ (also J.B. Becker, unpublished studies). Furthermore, the difference between the intact males and the other 3 groups was present even when the intact females, GDX females and GDX males received a lower challenge dose of AMPH (also see refs. 14, 15). (2) For the ratings of overall stereotypy and repetitive head and limb movements (Fig. 1) there were significant group by test session interactions (profile analyses). This indicates that the females and GDX males differed from intact males in the rate of change in behavior with repeated AMPH treatment. Intact males were not just uniformly less responsive at all points in time. (3) Perhaps most convincing are the data on locomotor activity. There was no difference between the 4 groups on this measure following the first injection of AMPH, but with repeated exposure the groups differentiated. This provides further strong evidence that the groups differed in the susceptibility to sensitization (i.e. the propensity to change), and not just in AMPH metabolism or the acute response to $\mathrm{AMPH}^{56}$.

It is also unlikely that drug-environment conditioning ${ }^{51,64,72}$ played a major role in the sensitization reported here. Pseudoconditioned animals, which received saline in the test environment and AMPH in their home cage, did not differ from animals that received most of their AMPH injections in the test environment. Furthermore, an injection of saline administered 3-4 days following repeated AMPH treatment did not produce stereotyped behavior. This is in agreement with previous suggestions that drug-environment con- 
ditioning is not necessary for the development of sensitization $^{12,15,20,55,65,67}$ (also ref. 59 for review). Nevertheless, efforts were made to minimize drug-environment conditioning in the present study, and the long-term effects of repeated AMPH treatment may be greatly potentiated if appropriate drug-environment contingencies are established (e.g. ref. 70).

\section{Neural correlates of behavioral sensitization}

AMPH-pretreatment significantly enhanced striatal HVA concentrations and DA metabolite to DA ratios in intact female, GDX female and GDX male rats, but not intact male rats. Thus, those groups which showed the most robust behavioral sensitization also showed changes in striatal DA metabolism; whereas intact male animals showed less pronounced behavioral changes and no significant changes in DA metabolism. In some experimental situations DA metabolism may provide a sensitive index of DA utilization $^{8,40,71}$. Therefore, to the extent that an elevation in HVA levels and DA metabolite to DA ratios indicates increased DA utilization, AMPH pretreatment may have enhanced DA utilization preferentially in those groups showing the most robust behavioral changes. This interpretation must be considered preliminary, however, because in some situations DA metabolism can be dissociated from DA utilization or release (e.g. ref. 17). But regardless of the interpretation of changes in DA metabolism, the results do show for the first time that the effects of sex and gonadal hormones on at least one neurochemical correlate of sensitization are consistent with their effects on behavioral sensitization (also see ref. 15).

The failure of repeated AMPH treatment to change basal levels of striatal DA metabolism or DA utilization in intact males has been reported previously ${ }^{15,39,47,50}$. This raises the question: if an enhancement in striatal DA utilization/release is causally related to the development of behavioral sensitization, why do both males and females show behavioral sensitization (albeit males to a lesser degree) but only females and GDX males show evidence of increased striatal DA utilization? There are a number of possible answers to this question. One possibility is that enhanced striatal DA utilization/release is not causally related to behavioral sensitization. However, AMPH-stimulated striatal DA utilization/release is enhanced in both male ${ }^{37,50,58}$ and female rats pretreated with AMPH ${ }^{16,61}$. Therefore, behavioral sensitization is accompanied by enduring changes in striatal DA release in both males and females, but such changes may not be obvious in the absence of a subsequent challenge stimulus. Perhaps under basal conditions the changes in striatal DA activity produced by prior AMPH treatment are minimal and only apparent in the most highly sensitized groups.

Another factor that may contribute to the differences between intact male animals and the other 3 groups is suggested by the analysis of subgroups. Following repeated AMPH treatment intact males were divisible into two neurochemically distinguishable subgroups. One subgroup was highly sensitized, as indicated by the emergence of a multiphasic pattern of AMPH-induced behavior, characterized in part by highly focused stereotypy ${ }^{67}$. The other subgroup did not develop this multiphasic pattern of behavior, and was thus presumably less sensitized. The former subgroup had significantly higher DOPAC/DA ratios than the latter. In contrast, it was not possible to subdivide the intact female, GDX female or GDX male groups into two neurochemically distinct subgroups in this fashion. This suggests that the intact male population is in some sense more heterogeneous than the other 3 populations (also see Camp and Robinson ${ }^{15}$ ). This greater heterogeneity may make it more difficult to identify neurochemical correlates of behavioral sensitization in intact males than in females or GDX males. It is interesting to speculate that individual differences in circulating androgens contribute to individual differences in the susceptibility to sensitization, and that $\mathrm{HI}$ activity males have lower concentrations of androgens than LO activity males.

Evidence that repeated intermittent AMPH treatment produces changes in neural systems other than the nigrostriatal DA system is quite limited ${ }^{59,60}$. In the present study there were indications that striatal and nucleus accumbens serotonin metabolism was enhanced by AMPH pre- 
treatment. Although this observation needs to be replicated, it is consistent with an earlier report of increased $\left[{ }^{3} \mathrm{H}\right]$ serotonin release into the lateral ventricles in AMPH-pretreated rats ${ }^{69}$. There is much more evidence for sensitization-related increases in nucleus accumbens DA utilization/release, especially following a subsequent challenge stimulus ${ }^{21,31-33,38,50,56}$. As with the striatum, reports of sensitization-related changes in basal nucleus accumbens DA activity are rare $^{74}$. As discussed above, however, this may be because less highly sensitized and more variable male animals have been used in most studies. AMPH pretreatment did significantly enhance nucleus accumbens DA metabolite concentrations in females (also see ref. 63).

\section{Relations between the sensitization to AMPH and stress}

It has been suggested that the enduring changes in brain and behavior produced by repeated intermittent AMPH treatment may not be unique to the psychopharmacology of AMPH, but due to its action as a stressor ${ }^{1,2,3,52}$. This idea is supported by evidence for 'cross-sensitization' between AMPH and stress. That is, prior exposure to a variety of stressors enhances the behavioral and neurochemical effects of subsequent AMPH treatment ${ }^{3,4,28,57,77}$, and prior exposure to AMPH enhances behavioral and neurochemical effects of subsequent stress ${ }^{4,62}$.

In the present study it was hypothesized that if AMPH and stress are interchangeable in producing sensitization, then sex and gonadal hormones should have similar effects on the sensitization produced by either 'agent'. The results support this hypothesis. Intact females, GDX females and GDX males, but not intact males, showed a significant enhancement in AMPHinduced stereotypy after only 5 days of restraint stress, as indicated by ratings of overall stereotypy and repetitive head and limb movements. As with the sensitization to AMPH, the differences between males and females appear to be quantitative, not qualitative, because 15 days of restraint stress enhanced these same responses in intact males. We are aware of only one other study in which the influence of sex and gonadal hormones on sensitization to repeated intermittent stress was examined (refs. 26, 27 for review), but the pattern of results is very similar to that reported here. Hennessy et al. ${ }^{26}$ found that previous footshock experience enhanced the elevation in corticosterone produced by subsequent footshock in intact female, GDX female and GDX male mice, but not in intact male mice. Thus it appears that circulating male, but not female gonadal hormones attenuate the sensitization produced by either repeated AMPH treatment or repeated stress.

In summary, it was found that: (1) females show more robust behavioral sensitization to AMPH than males, and prior AMPH treatment produces an enduring enhancement in basal striatal and nucleus accumbens DA metabolism in females, but not males. These results confirm and extend our earlier findings ${ }^{15,55,61,63}$. (2) This sex difference appears to be due to the attenuation of sensitization by endogenous testicular hormones, because GDX of female rats had no effect on sensitization, whereas GDX of males enhanced behavioral sensitization and a neurochemical correlate of sensitization. (3) Males appear to be a more heterogeneous population than females or GDX animals, because it was possible to subdivide the intact male group into two neurochemically distinct subgroups based on degree of sensitization. The other 3 groups were not divisible in this fashion. (4) Prior restraint stress also enhanced the behavioral response to subsequent AMPH treatment, and sex and testicular hormones modulated the sensitization to stress in the same fashion as sensitization to AMPH. It is concluded that individual differences in the susceptibility to sensitization by either AMPH or stress may be in part due, either directly, or indirectly to individual differences in the concentration of circulating androgens. Whether the effects of sex and gonadal hormones described here are related to sex differences in psychiatric disorders that can be precipitated by AMPH or stress, and are thought to involve brain DA dysfunction, is unknown (e.g. refs. $9,10,29,42,43,75,76)$. Nevertheless, the data suggest that studies on the interaction between biological and environmental factors contributing 
to individual variation in the susceptibility to sensitization will be valuable in trying to understand what makes some individuals very sensitive, and others quite resistant, to the psychotogenic effects of stimulant drugs and stress.

\section{ACKNOWLEDGEMENTS}

This research was submitted by D.M.C. in partial fulfillment of requirements for a Ph.D. in Psychology (Psychobiology) at The University of Michigan, Ann Arbor. Preliminary versions were reported earlier: Soc. Neurosci. Abstr., 11 (1985) 550 ; ibid, 12 (1986) 1481. The research was supported by Grants from the NIH (MH37277), Scottish Rite Schizophrenia Research Program and Rackham School of Graduate Studies. T.E.R. was supported by a Research Career Development Award (NS00844). We thank Dr. J.B. Becker for her comments and advice during all stages of the project.

\section{REFERENCES}

1 Antelman, S.M. and Chiodo, L.A., Amphetamine as a stressor. In I. Creese (Ed.), Stimulants: Neurochemical, Behavioral, and Clinical Perspectives, Raven, New York, 1983, pp. 269-299.

2 Antelman, S.M. and Chiodo, L.A., Stress: its effect on interactions among biogenic amines and role in the induction and treatment of disease. In L.L. Iversen and S.H. Snyder (Eds.), Handbook of Psychopharmacology, Vol. 18, Plenum, New York, 1984, pp. 279-341

3 Antelman, S.M. and Eichler, A.J., Persistent effects of stress on dopamine-related behaviors: clinical implications. In E. Usdin, I.J. Kopin and J. Barchas (Eds.), Catecholamines: Basic and Clinical Frontiers, Pergamon, New York, 1979, pp. 1759-1761.

4 Antelman, S.M., Eichler, A.J., Black, C.A. and Koçan, D., Interchangeability of stress and amphetamine in sensitization, Science, 207 (1980) 329-331.

5 Becker, J.B. and Beer, M.E., The influence of estrogen on nigrostriatal dopamine activity: behavioral and neurochemical evidence for both pre- and postsynaptic components, Behav. Brain Res., 19 (1986) 27-33.

6 Becker, J.B. and Ramirez, V.D., Sex differences in the amphetamine-stimulated release of catecholamines from rat striatal tissue in vitro, Brain Res., 204 (1981) 361-372.

7 Becker, J.B., Robinson, T.E. and Lorenz, K.A., Sex differences and estrous cycle variations in amphetamineelicited rotational behavior, Eur. J. Pharmacol., 80 (1982) $65-72$.
8 Blanc, G., Hervé, D., Simon, H., Lisoprawski, A., Glowinski, J. and Tassin, J.P., Response to stress of mesocortico-frontal dopaminergic neurones in rats after long-term isolation, Nature (Lond.), 284 (1980) 265-267.

9 Bowers Jr., M.B., Swigar, M.E. and Jatlow, P.I., Sex differences in plasma homovanillic acid in acute psychosis, New Eng. J. Med., 308 (1983) 845-846.

10 Bowers Jr., M.B., Swigar, M.E., Jatlow, P.I. and Goicoechea, N., Plasma catecholamine metabolites and early response to haloperidol, J. Clin. Psychiat., 45 (1984) 248-251.

11 Brass, C.A. and Glick, S.D., Sex differences in druginduced rotation in two strains of rats, Brain Res., 223 (1981) 229-234.

12 Browne, R.G. and Segal, D.S., Metabolic and experiential factors in the behavioral response to repeated amphetamine, Pharmacol Biochem. Behav., 6 (1977) 545-552.

13 Camp, D.M., Becker, J.B. and Robinson, T.E., Sex differences in the effects of gonadectomy on amphetamineinduced rotational behavior in rats, Behav. Neural Biol, 46 (1986) 491-495.

14 Camp, D.M. and Robinson, T.E., Sex differences in an animal model of amphetamine psychosis, Soc. Neurosci. Abstr., 11 (1985) 550.

15 Camp, D.M. and Robinson, T.E., Susceptibility to sensitization. I. Sex differences in the enduring effects of chronic amphetamine treatment on locomotion, stereotyped behavior and brain monoamines, Behav. Brain Res., 30 (1988) 55-68

16 Castañeda, E., Becker, J.B., Wilcox, R. and Robinson, T.E., Sensitization to amphetamine is accompanied by enhanced striatal dopamine release, Soc. Neurosci. Abstr., 11 (1985) 499.

17 Commissiong, J.W., Monoamine metabolites: their relationship and lack of relationship to monoaminergic neuronal activity, Biochem. Pharmacol,, 34 (1985) 1127-1131.

18 Conney, P.H., Pharmacological implications of microsomal enzyme induction, Pharmacol. Rev., 19 (1967) 317-366.

19 Costall, B. and Naylor, R.J., Mesolimbic and extrapyramidal sites for the mediation of stereotyped behavior patterns and hyperactivity by amphetamine and apomorphine in the rat. In E.H. Ellinwood and M.M. Kilbey (Eds.), Cocaine and Other Stimulants, Plenum, New York, 1977, pp. 47-76.

20 Echols, S.D., Circling of mice bearing unilateral striatal lesions: development of increased response to D-amphetamine, Life Sci., 21 (1977) 563-568.

21 Eichler, A.J. and Antelman, S.M., Sensitization to amphetamine and stress may involve nucleus accumbens and medial frontal cortex, Brain Res., 197 (1979) 412-416.

22 Eichler, A.J., Antelman, S.M. and Black, C.A., Amphetamine stereotypy is not a homogeneous phenomenon: sniffing and licking show distinct profiles of sensitization and tolerance, Psychopharmacology, 68 (1980) 287-290. 
23 Ellinwood Jr., E.H. and Balster, R.L., Rating the behavioral effects of amphetamine, Eur. J. Pharmacol., 28 (1974) 35-41.

24 Goy, R.W. and McEwen, B.S., Sexual Differentiation of the Brain, Cambridge, MA, MIT Press, 1980.

25 Heffner, T.G., Hartman, J.A. and Seiden, L.S., A rapid method for the regional dissection of the rat brain, Pharmacol. Biochem. Behav., 13 (1980) 453-456.

26 Hennessy, J.W., Levin, R. and Levine, S., Influence of experiential factors and gonadal hormones on pituitaryadrenal response of the mouse to novelty and electric shock, J. Comp. Physiol. Psychol., 91 (1977) 770-777.

27 Hennessy, J.W. and Levine, S., Stress, arousal and the pituitary-adrenal system: a psychoendocrine hypothesis. In J.M. Sprague and A.N. Epstein (Eds.), Progress in Psychobiology and Physiological Psychology, Vol. 8, 1979, pp. 133-178.

28 Herman, J.P., Stinus, L. and LeMoal, M., Repeated stress increases locomotor response to amphetamine, Psychopharmacology, 84 (1979) 431-435.

29 Hogarty, G.E., Goldberg, S.C., Schooler, N.R. and Ulrich, R.F., Drug and sociotherapy in the after-care of schizophrenic patients, Arch. Gen. Psychiatry, 31 (1974) 603-608.

30 Iversen, S.D., Brain dopamine systems and behavior. In L.L. Iversen, S.D. Iversen and S.H. Snyder (Eds.), Handbook of Psychopharmacology, Vol. 8, Plenum, New York, 1977, pp. 333-383.

31 Kalivas, P.W., Sensitization to repeated enkephalin administration into the ventral tegmental area of the rat. II. Involvement of the mesolimbic dopamine system, J. Pharmacol. Exp. Ther., 235 (1985) 544-550.

32 Kalivas, P.W., Richardson-Carlson, R. and Van Orden, G., Cross-sensitization between foot-shock stress and enkephalin-induced motor activity, Biol. Psychiatry, 21 (1986) 939-950.

33 Kalivas, P.W. and Taylor, S., Behavioral and neurochemical effect of daily injection with neurotensin into the ventral tegmental area, Brain Res., 358 (1985) 70-76.

34 Kato, R., Sex-related differences in drug metabolism, Drug Metabol. Rev., 3 (1974) 1-32.

35 Kelly, P.H., Drug-induced motor behavior. In L.L. Iversen and S.H. Snyder (Eds.), Handbook of Psychopharmacology, Vol.8, New York, Plenum, 1977, pp. 295-331.

36 Klawans, H.L. and Margolin, D.I., Amphetamine-induced dopaminergic hypersensitivity in Guinea pigs, Arch. Gen. Psychiatry, 32 (1975) 725-732.

37 Kolta, M.G., Shreve, P., De Souza, V. and Uretsky, N.J., Time course of the development of the enhanced behavioral and biochemical responses to amphetamine after pretreatment with amphetamine, Neuropharmacology, 24 (1985) 823-829.

38 Kolta, M.G., Shreve, P. and Uretsky, N.J., Effect of methylphenidate pretreatment on the behavioral and biochemical responses to amphetamine, Eur. J. Pharmacol., 117 (1985) 279-282.
39 Kuczenski, R. and Leith, N.J., Chronic amphetamine: is dopamine a link in or mediator of the development of tolerance and reverse tolerance? Pharmacol. Biochem. Behav., 15 (1981) 405-413.

40 Lavielle, S., Tassin, J.P., Thierry, A.M., Blanc, G., Herve, D., Barthelemy, C. and Glowinski, J., Blockade by benzodiazepines of the selective high increase in dopamine turnover induced by stress in mesocortical dopaminergic neurons of the rat, Brain Res., 168 (1978) 585-594.

41 Leith, N.J. and Kuczenski, R., Two dissociable components of behavioral sensitization following repeated amphetamine administration, Psychopharmacology, 76 (1982) 310-315.

42 Lewine, R.R.J., Sex differences in schizophrenia: timing or subtypes? Physiol. Bull., 90 (1981) 432-444.

43 Loranger, A.W., Sex differences in age at onset of schizophrenia, Arch. Gen. Psychiatry, 41 (1984) 157-161.

44 Magos, L., Persistence of the effect of amphetamine on stereotyped activity in rats, Eur. J. Pharmacol., 6 (1969) 200-201.

45 Martres, M.P., Costentin, J., Baudry, M., Marcais, H., Protais, P. and Schwartz, J.C., Long-term changes in the sensitivity of pre- and postsynaptic dopamine receptors in mouse striatum evidenced by behavioral and biochemical studies, Brain Res., 136 (1977) 319-337.

46 Meyer Jr., E.M. and Lytle, L.D., Sex-related differences in the physiological disposition of amphetamine and its metabolites in the rat, Proc. West. Pharmacol. Soc., 21 (1978) 313-316.

47 Mittelman, G., Castañeda, E., Robinson, T.E. and Valenstein, E.S., The propensity for non-regulatory ingestive behavior is related to differences in dopamine systems: behavioral and biochemical evidence, Behav. Neurosci., 100 (1986) 213-220.

48 Moore, K.E. and Kelly, P.H., Biochemical pharmacology of mesolimbic and mesocortical dopamine neurons. In M.A. Lipton, A. DiMascio and K.F. Killam (Eds.), Psychopharmacology: A Generation of Progress, Raven, New York, 1978, pp. 221-234.

49 Morrison, D.F., Multivariate Statistical Methods, McGraw-Hill, New York, 1967.

50 Nishikawa, T., Mataga, N., Takashima, M. and Toru, M., Behavioral sensitization and relative hyperresponsiveness of striatal and limbic dopaminergic neurons after repeated methamphetamine treatment, Eur. J. Pharmacol., 88 (1983) 195-203.

51 Pickens, R. and Dougherty, J.A., Conditioning of the activity effects of drugs. In T.I. Thompson and R. Pickens (Eds.), Stimulus Properties of Drugs, Appleton-CenturyCrofts, New York, pp. 39-50.

52 Post, R.M., Cocaine psychosis: a continuum model, Am. J. Psychiatry, 132 (1975) 225-231.

53 Ranje, C. and Ungerstedt, U., Chronic amphetamine treatment: vast individual differences in performing a learned response, Eur. J. Pharmacol., 29 (1974) 307-311.

54 Rebec, G.V. and Segal, D.S., Apparent tolerance to some aspects of amphetamine stereotypy with long-term treatment, Pharmacol. Biochem. Behav., 13 (1980) 793-797. 
55 Robinson, T.E., Behavioral sensitization: characterization of enduring changes in rotational behavior produced by intermittent injections of amphetamine in male and female rats, Psychopharmacology, 84 (1984) 466-475.

56 Robinson, T.E., Stimulant drugs and stress: factors influencing the susceptibility to sensitization. In C. Barnes and P. Kalivas (Eds.), Sensitization of the Nervous System, Telford, Caldwell, NJ, in press.

57 Robinson, T.E., Angus, A.L. and Becker, J.B., Sensitization to stress: the enduring effects of prior stress on amphetamine-induced rotational behavior, Life Sci., 37 (1985) 1039-1042.

58 Robinson, T.E. and Becker, J.B., Behavioral sensitization is accompanied by an enhancement in amphetaminestimulated dopamine release from striatal tissue in vitro, Eur. J. Pharmacol., 85 (1982) 253-254.

59 Robinson, T.E. and Becker, J.B., Enduring changes in brain and behavior produced by chronic amphetamine administration: a review and evaluation of animal models of amphetamine psychosis, Brain Res. Rev., 11 (1986) 157-198.

60 Robinson, T.E., Becker, J.B., Moore, C.J., Castañeda, E. and Mittelman, G., Enduring enhancement in frontal cortex dopamine utilization in an animal model of amphetamine psychosis, Brain Res., 343 (1985) 374-377.

61 Robinson, T.E., Becker, J.B. and Presty, S.K., Long-term facilitation of amphetamine-induced rotational behavior and striatal dopamine release produced by a single exposure to amphetamine: sex differences, Brain Res., 253 (1982) 231-241.

62 Robinson, T.E., Becker, J.B., Young, E.A., Akil, H. and Castañeda, E., The effects of footshock stress on regional brain dopamine metabolism and pituitary $\beta$-endorphin release in rats previously sensitized to amphetamine, Neuropharmacology, 26 (1987) 679-691.

63 Robinson, T.E. and Camp, D.M., Long-lasting effects of escalating doses of $\mathrm{D}$-amphetamine on brain monoamines, amphetamine-induced stereotyped behavior and spontaneous nocturnal locomotion, Pharmacol. Biochem. Behav., 26 (1987) 821-827.

64 Schiff, S.R., Conditioned dopaminergic activity, Biol. Psychiatry, 17 (1982) 135-154.

65 Segal, D.S., Behavioral and neurochemical correlates of repeated D-amphetamine administration. In A.J. Mandell (Ed.), Neurobiological Mechanisms of Adaptation and Behavior, Raven, New York, 1975, pp. 247-262.

66 Segal, D.S. and Kuczenski, R., Individual differences in responsiveness to single and repeated amphetamine administration: behavioral characteristics and neurochemical correlates, J. Pharmacol. Exp. Ther., 242 (1987) 917-926.
67 Segal, D.S. and Mandell, A.J., Long-term administration of D-amphetamine: progressive augmentation of motor activity and stereotypy, Pharmacol. Biochem. Behav., 2 (1974) 249-255.

68 Shannon, N.J., Gunnet, J.W. and Moore, K.E., A comparison of biochemical indices of 5-hydroxytryptaminergic neuronal activity following electrical stimuation of the dorsal raphe nucleus, J. Neurochem., 47 (1986) 958-965.

69 Sparber, S.B. and Tilson, H.A., The releasability of central norepinephrine and serotonin by peripherally administered D-amphetamine before and after tolerance, Life Sci., 11 (1972) 1059-1067.

70 Stewart, J. and Vezina, P., Environment-specific enhancement of the hyperactivity induced by systemic or intra-VTA morphine injections in rats pre-exposed to amphetamine, Psychobiology, 15 (1987) 144-153.

71 Szentendrei, T., Herman, J.P., Kanyicska, B. and Fekete, M.I.K., Stress-induced changes in dopamine metabolism of rat brain cortex as well as plasma corticosterone and prolactin levels - effects of diazepam and tofisopam. In E. Usdin, R. Kvetnansky and I. Kopin (Eds.), Catecholamines and Stress: Recent Advances, Elsevier, Amsterdam, 1980, pp. 161-166.

72 Tilson, H.A. and Rech, R.H., Conditioned drug effects and absence of tolerance to D-amphetamine-induced motor activity, Pharmacol. Biochem. Behav., 1 (1973) 149-153.

73 Ungerstedt, U., Central dopamine mechanisms and unconditioned behavior. In A.S. Horn, J. Korf and B.H. Westerink (Eds.), The Neurobiology of Dopamine, Academic, London, 1979, pp. 577-596.

74 Watanabe, H., Subchronic methamphetamine treatment selectively attenuates apomorphine-induced decrease in 3,4-dihydroxyphenylacetic acid level in mesolimbic dopaminergic regions, Life Sci., 37 (1985) 2319-2325.

75 Watt, D.C., Katz, K. and Stepherd, M., The natural history of schizophrenia: a 5-year prospective follow-up of a representative sample of schizophrenics by means of a standardized clinical and social assessment, Psychol. Med., 13 (1983) 663-670.

76 Watt, D.C. and Szulecka, T.K., The effect of sex, marriage and age at first admission on the hospitalization of schizophrenics during 2 years following discharge, $P s y-$ chol. Med., 9 (1979) 529-539.

77 Wilcox, R.A., Robinson, T.E. and Becker, J.B., Enduring enhancement in amphetamine-stimulated striatal dopamine release in vitro produced by prior exposure to amphetamine or stress in vivo, Eur. J. Pharmacol., 124 (1986) $375-376$ 